\title{
Imaging Diagnosis of Perianal Leiomyoma: A Case Report
}

\author{
Enrique González-Díaz ${ }^{1}$, Blanca García Cengotitabengoa², Ana Belen Dominguez Carbajo ${ }^{3}$, \\ Camino Fernández Fernández ${ }^{2}$, A. Fernández Corona ${ }^{2}$ \\ ${ }^{1}$ Pelvic Floor Unit, Department of Obstetrics and Gynaecology, ${ }^{2}$ Department of Obstetrics and Gynaecology, ${ }^{3}$ Department of \\ Gastroenterology, Complejo Asistencial Universitario de León (CAULE), León, Spain
}

A leiomyoma is a benign mesenchymal neoplasm that usually develops where smooth muscle is present. In this report, we present the case of a 75-year-old woman who sought medical attention due to pelvic organ prolapse and urinary incontinence, and without defecatory symptoms. Both pelvic floor ultrasound and magnetic resonance imaging (MRI) examination showed a well-defined mass in the ischioanal fossa, eventually diagnosed as a perianal leiomyoma. It is considered a rare entity because of its location involving the anal sphincter and clinical features. We describe the ultrasonographic and MRI findings of this perianal leiomyoma, together with differential diagnoses and immunohistochemical characterization.

\section{Keywords: Anus neoplasms; Gastrointestinal neoplasms; Leiomyoma; Diagnostic imaging}

\section{INTRODUCTION}

Leiomyoma is a benign soft tissue tumor of mesenchymal origin that derives from smooth muscle fibers and develops in the regions where these fibers are present $[1,2]$. Their pathogenesis remains obscure. In the digestive tract, the anorectal location is uncommon and is usually diagnosed late due to intraluminal growth in over $50 \%$ of the cases [2]. Reports of perianal leiomyomas are sparse in the literature [1-7]. Our aims of this case report are to present a perianal leiomyoma as a rare tumor in the gastrointestinal tract and to report the tumor on imaging diagnosis using pelvic floor ultrasound and magnetic resonance imaging (MRI). We also discuss the differential diagnosis when we meet a firm tumor around the perianal space.

\section{CASE REPORT}

We present the case of a 75-year-old woman who was admitted to

Received: Jul 14, 2020 - Revised: Oct 9, 2020 - Accepted: Oct 13, 2020 Correspondence to: Enrique González-Díaz, M.D.

Servicio de Obstetricia y Ginecología, Complejo Asistencial Universitario de León (CAULE), C/ Altos de Nava S/N, 24080 León, Spain

E-mail: enriquegonzalezdiaz@hotmail.com

ORCID: https://orcid.org/0000-0002-4528-2473

(C) 2021 The Korean Society of Coloproctology

This is an open-access article distributed under the terms of the Creative Commons Attribution NonCommercial License (https://creativecommons.org/licenses/by-nc/4.0) which permits unrestricted noncommercial use, distribution, and reproduction in any medium, provided the original work is properly cited. the Pelvic Floor Unit of our institution due to pelvic organ prolapse and urinary incontinence. Written informed consent was obtained for publication of this case report and accompanying images.

The patient did not present symptoms related to defecation, as tenesmus, rectorrhagia, proctalgia, constipation, or incontinence. Physical examination revealed a cystocele and uterine prolapse grade III (according to the Baden-Walker scoring system), associated with stress urinary incontinence. Pelvic floor ultrasound, with endovaginal probe, showed a well-defined hypoechoic mass measuring $3 \times 4 \mathrm{~cm}$ in the right ischioanal fossa. The mass seemed to be in continuity with the external anal sphincter at the level of the midlateral third of right anal canal but a beak sign between the mass and the external anal sphincter revealed that they were separate entities (Fig. 1A). Power-Doppler ultrasound showed a peripheral pattern which confirmed internal sphincter origin (Fig. 1B) (Supplementary Video 1).

Additionally, an MRI examination was performed (Fig. 2). On T1 weighted imaging, the mass showed homogeneous low signal intensity, similar to that of pelvic muscles. On T2 weighted imaging, the mass showed subtle heterogeneous high signal intensity compared with that of pelvic muscles and a thin rim with a low signal intensity at the peripheral portion of the mass. On contrastenhanced T1 weighted imaging with fat suppression, the mass showed a strong homogeneous enhancement without necrosis or cystic changes. There was a clear demarcation between the mass and the external anal sphincter, although there was a beak sign in the anal sphincter. The suspected imaging diagnosis was anal 

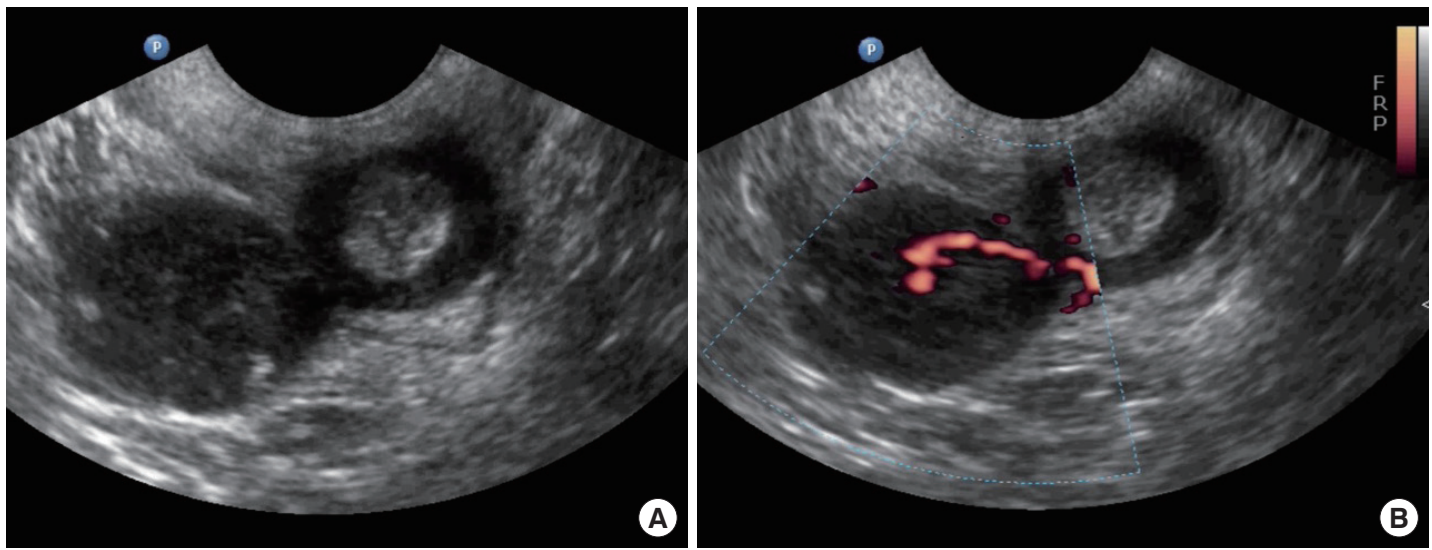

Fig. 1. (A) Introital ultrasound with endovaginal probe, showing the beak sign between the external anal sphincter and the mass. (B) PowerDoppler ultrasound with endovaginal probe reveals the internal sphincter origin of the leiomyoma.
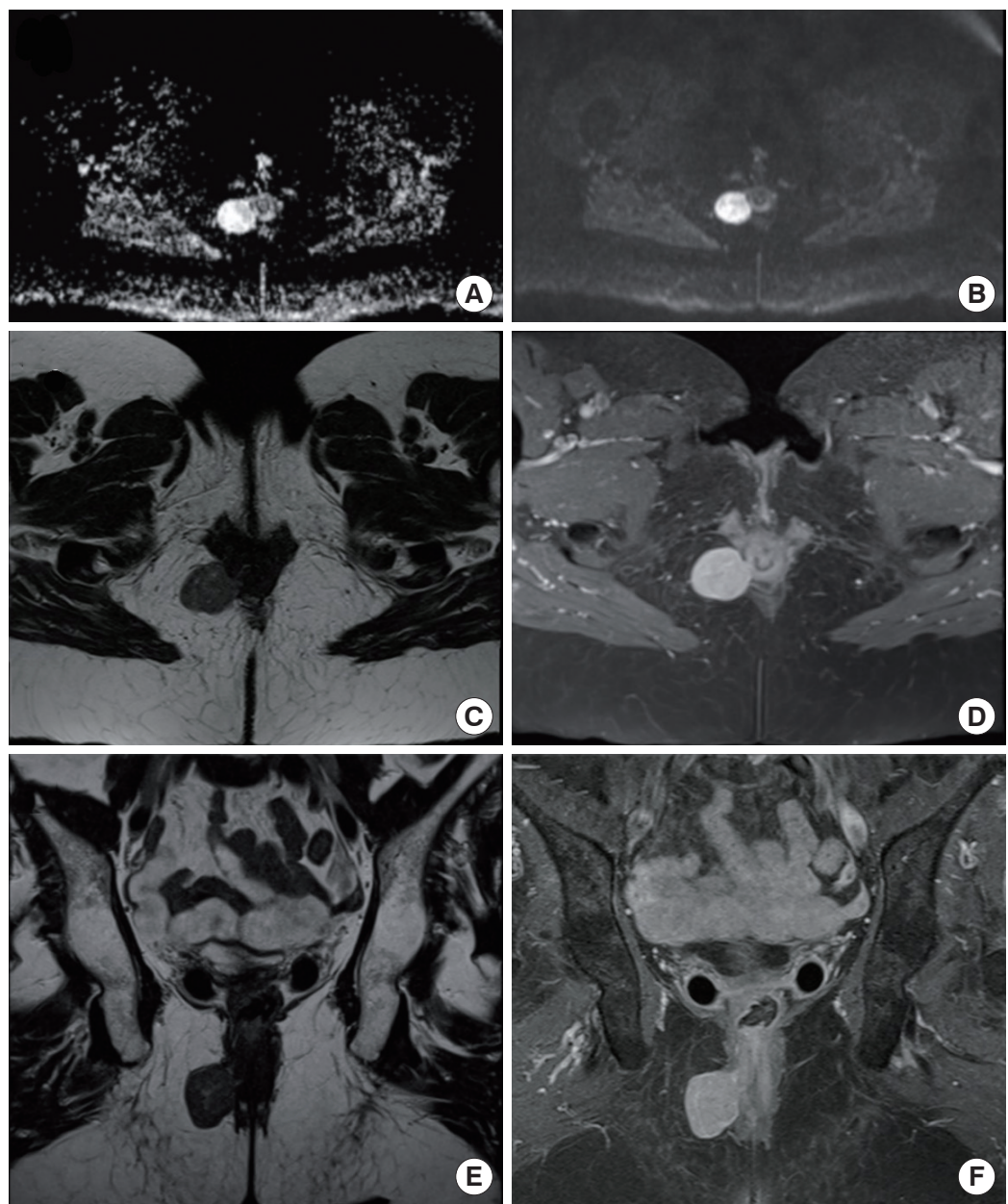

Fig. 2. Pelvic magnetic resonance imaging (MRI) images showing a solid and well-defined mass in the right ischioanal fossa, measuring $3.4 \times$ $2.9 \mathrm{~cm}$. (A) Diffusion-weighted image with no restriction signs. (B) Turbo-spin-echo (fat-sat) T1-weighted sequence after gadolinium contrast administration, showing an intense uniform enhancement. (C, E) Axial and coronal T1-weighted sequences. The mass shows homogeneous and low signal intensity. (D, F) Turbo-spin-echo (fat-sat) T1-weighted sequence after paramagnetic contrast administration, in axial and coronal planes, showing an intense uniform enhancement. 


\section{Coloproctology
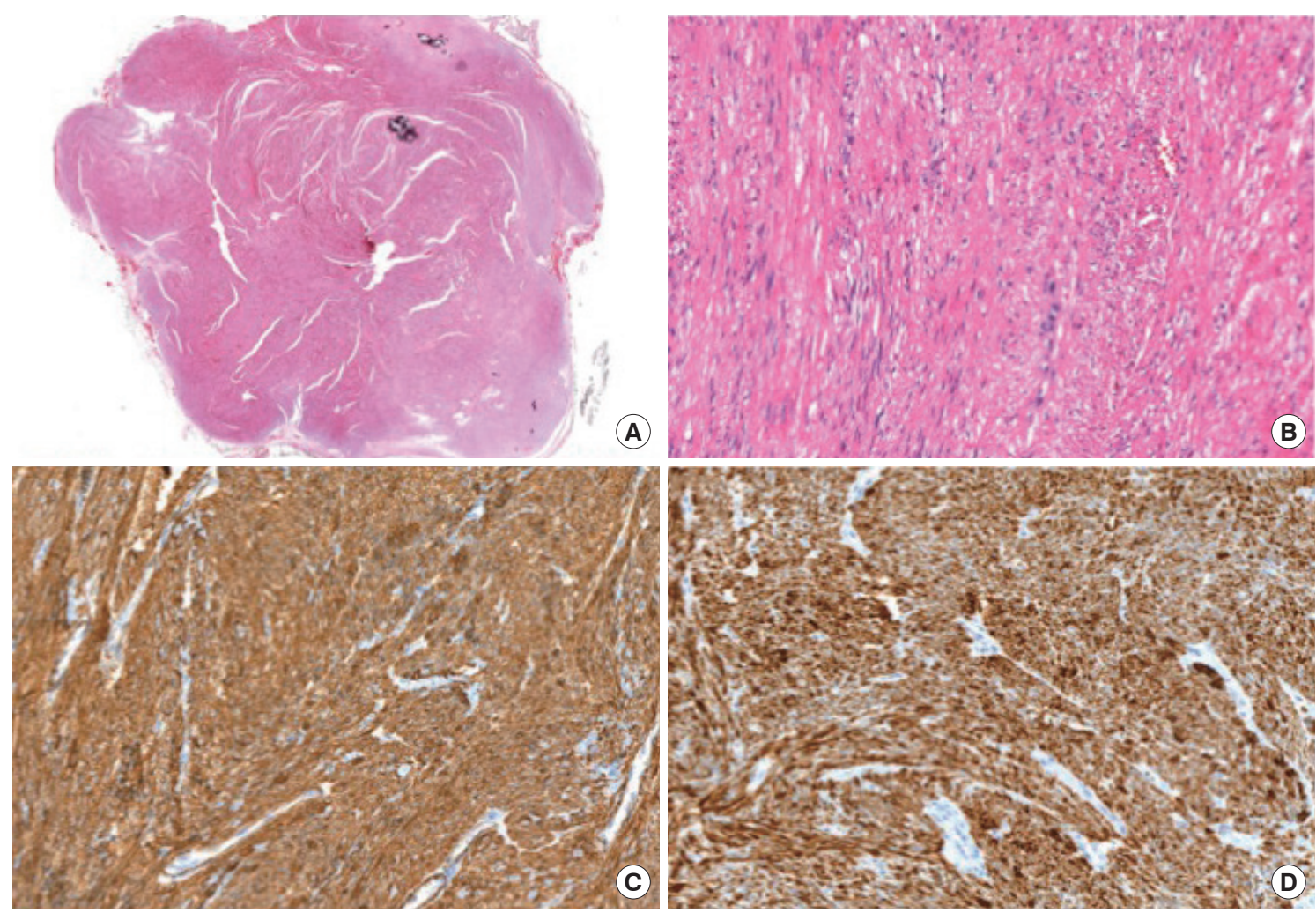

Fig. 3. (A) Microscopic view after section $(H \& E, \times 200)$. (B) Neoplastic proliferation is made up of short fascicles of fusiform cells, without atypia $(H \& E, \times 200)$. (C) Immunohistochemical positivity for actin $(\times 200)$. (D) Immunohistochemical positivity for desmin $(\times 200)$.

leiomyoma.

Surgery was performed with a para-anal incision. The external anal sphincter was largely intact even though the tumor emerged through it. The mass was covered by a thin capsule, and a complete extracapsular dissection was performed. The external anal sphincter was dissected for mass removal and was eventually repaired. The pathological specimen was a gray-to-white solid mass measuring $3.3 \times 2.7 \mathrm{~cm}$ in size (Fig. $3 \mathrm{~A}$ ). The mass was covered by a thin fibrous pseudocapsule, which was seen as a thin rim of low signal intensity on T2 weighted images. Neither cystic changes nor necrosis were noted. On light microscopy, the tumor consisted of interlacing fascicles of spindle cells; neither cellular atypia nor mitoses were noted (Fig. 3B). On immunohistochemistry, smooth muscle actin (Fig. 3C) and desmin (Fig. 3D) were positive and CD117 (KIT) and S100 were negative. Tumor cells also stained positively for estrogen and progesterone receptors. It was finally confirmed as a vascular leiomyoma, focally calcified and covered by a thin pseudocapsule.

Subsequently, surgical treatment was completed with vaginal hysterectomy, anterior colporrhaphy and by placing a transobturator tape.

To this day, no tumor recurrence is noted, being the patient asymptomatic with complete sphincter continence.

\section{DISCUSSION}

Leiomyoma was the first described by Virchow in 1854, defining it as a benign tumor of mesenchymal origin dependent on smooth muscle fibers. It represents approximately $3.8 \%$ of all the benign, soft tissue tumors and its pathogeny continues to be debated today $[2,3]$. Leiomyomas can occur in various organs and may develop in deep soft tissues. Those deep soft tissue leiomyomas can be classified into leiomyomas of somatic soft tissue and retroperitoneal-abdominal leiomyomas. This last type of myomas usually occurs in the pelvic retroperitoneum and affects females preferentially, being histologically similar to uterine leiomyomas and positive for hormone receptors. The most commonly affected organ in the gastrointestinal tract is the stomach, followed by the small bowel. The esophagus, colon, and rectum are less frequent locations [8]. The anorectal location presents in under $0.1 \%$ and it is considered an extraordinary entity with an overall rectal tumor incidence of 1:2,000. Tumor growth is intraluminal in $50 \%$ of the cases, extrarectal in 30\%, intra- and extraluminal in 10\%, and intramural in the remaining $10 \%$ [9].

Among the anorectal leiomyomas, those related to the anal canal are even more uncommon. There are seven reported cases of perianal leiomyomas (Table 1) that have been confirmed by im- 
Table 1. Resume of seven reported cases of perianal leiomyomas

\begin{tabular}{|c|c|c|c|c|c|c|}
\hline Study & $\begin{array}{l}\text { Publication } \\
\text { year }\end{array}$ & $\begin{array}{l}\text { Age }(y r) / \\
\text { sex }\end{array}$ & Symptom & Physical examination & Capsule & Immunohistochemistry \\
\hline Huilgol et al. [1] & 2003 & 42 & $\begin{array}{c}\text { Painful right buttock } \\
\text { mass }\end{array}$ & A rubbery $9 \times 8 \times 6$-cm mass & Pseudocapsule & $\begin{array}{l}\text { Actin and desmin positive } \\
\text { CD34 and CD117 negative }\end{array}$ \\
\hline Dasari et al. [2] & 2007 & 45/female & Painless swelling & 65-mm soft tissue mass & Pseudocapsule & $\begin{array}{l}\text { Actin and desmin positive } \\
\text { Estrogen and progesterone } \\
\text { receptors positive } \\
\text { CD117 negative }\end{array}$ \\
\hline Kim et al. [3] & 2009 & 30/female & Palpable mass & $46 \times 35-\mathrm{mm}$ firm mass & $\begin{array}{c}\text { Thin } \\
\text { pseudocapsule }\end{array}$ & $\begin{array}{l}\text { Actin and desmin positive } \\
\text { CD117 and S100 negative }\end{array}$ \\
\hline Canda et al. [4] & 2010 & $37 / \mathrm{male}$ & $\begin{array}{l}\text { Gradually enlarging } \\
\text { anal mass }\end{array}$ & $80 \times 40-\mathrm{mm}$ solid mass & Capsule & $\begin{array}{l}\text { Actin, desmin, and Caldesmon positive } \\
\text { CD117, CD34, and S100 negative. }\end{array}$ \\
\hline Alonso Gómez et al. [5] & 2011 & $54 /$ male & Palpable mass & $43 \times 31-\mathrm{mm}$ solid mass & $\begin{array}{c}\text { Fibrous } \\
\text { pseudocapsule }\end{array}$ & $\begin{array}{l}\text { Actin and desmin positive } \\
\text { CD117, CD34, and S100 negative }\end{array}$ \\
\hline Sun et al. [6] & 2017 & 28/female & Perianal mass & $70 \times 40-\mathrm{mm}$ firm mass & Capsule & $\begin{array}{l}\text { Actin, desmin, and calpomin positive } \\
\text { CD117, CD31, CD34, CD68, CD163, } \\
\text { S100, EMA, and Dog1 negative }\end{array}$ \\
\hline Dagmura et al. [7] & 2019 & $51 / \mathrm{male}$ & $\begin{array}{l}\text { History of perianal } \\
\text { purulent discharge }\end{array}$ & $\begin{array}{l}35 \times 24-\mathrm{mm} \text { rubbery mass and } \\
\text { external orifice of the perianal } \\
\text { fistula }\end{array}$ & Pseudocapsule & $\begin{array}{l}\text { Actin and desmin positive } \\
\text { CD117, CD34, and S100 negative }\end{array}$ \\
\hline Current study & 2021 & 75/female & $\begin{array}{l}\text { Pelvic organ prolapse } \\
\text { and urinary incontinence }\end{array}$ & $33 \times 27-\mathrm{mm}$ solid mass & $\begin{array}{l}\text { Thin } \\
\text { pseudocapsule }\end{array}$ & $\begin{array}{l}\text { Actin and desmin positive } \\
\text { Estrogen and progesterone receptors } \\
\text { positive } \\
\text { CD117 and S100 negative }\end{array}$ \\
\hline
\end{tabular}

EMA, Epithelial membrane antigen.

munohistochemical staining [1-7]. Before the development of immunohistochemical staining, characterization of leiomyomas was questionable. Similar to our case, all leiomyomas reported were presented as perianal homogeneous solid masses without necrosis or cystic changes, and a fibrous pseudocapsule.

The differential diagnoses for a perianal mass include gastrointestinal stromal tumors (GISTs), leiomyosarcomas, endometriomas, lipomas, liposarcomas, and fibrosarcomas. Most GISTs arise within the muscularis propria, and commonly have an exophytic growth pattern and manifest as dominant masses outside the organ of origin. Dominant intramural and intraluminal masses are less common radiologic manifestations [10]. These findings of anorectal GISTs were similar to the findings of anorectal leiomyomas published before the introduction of immunohistochemical staining with CD117 (KIT), a tyrosine kinase growth factor receptor. In fact, GISTs are nowadays differentiated from leiomyomas on the basis of immunohistochemical staining patterns, as leiomyomas are usually negative for CD117 (KIT) and S100, and positive for smooth muscle actin and desmin. Anorectal leiomyosarcomas usually present as intraluminal polypoid tumors, suggesting that these tumors might be related to the inner smooth muscle layer, and show aggressive imaging features such as direct invasion of adjacent structures [11]. Endometriomas can present as a perianal mass and may also involve the rectal sphincter. However, endometriomas usually develop following an episiotomy during vaginal delivery and show symptoms related to the menstrual cycle [12]. Lipomas and liposarcomas may also occur in the ischioanal fossa, although these are uncommon. MRI can identify the signal intensity of fatty tissue; however, it is limited in differentiating well-differentiated liposarcoma from lipoma [13]. Fibrosarcoma may present as a perianal mass and may also involve the anus. Infiltration into the anus and subcutaneous fat tissue may be present in fibrosarcoma [14].

The clinical course of perianal leiomyomas varies widely, and it is the location and vascularization that determine patient's symptomatology [11]. They are often asymptomatic in their initial stages. Later, when they reach significant sizes, anal and perineal pain, bowel transit alterations, pruritus, rectorrhagia or tenesmus are some of the most frequent symptoms for which the patient seeks medical attention. Our patient was asymptomatic, as she was probably in the initial stage of the disease.

Imaging techniques are useful for preoperative staging because they enable to define the relationship between the sphincters and urogenital tract. Preoperative studies performed allowed us to guide the diagnosis and plan the surgical intervention. A beak sign in ultrasound means that the origin of mass is in internal anal sphincter and muscle fibers of the external anal sphincter were stretched to allow passage through.

In relation to management, complete surgical resection of the tumor is the treatment of choice. Easily accessible intrarectal leio- 
myomas can be transanally resected. Low anterior resection or abdominoperineal amputation should be reserved for those cases in which local resection cannot be performed due to tumor size or wall involvement. Another approach should be contemplated, which could be transperineal, pararectal, or transvaginal, when the tumor is extrarectal [15].

These tumors recur in up to $40 \%$ of the cases and up to $10 \%$ use to recur as leiomyosarcomas; this appears to be related to incomplete resection or a size greater than $5 \mathrm{~cm}$. The fact that there is the possibility of recurrence, even in low-grade tumors, makes follow-up essential [16].

In conclusion, perianal leiomyoma is a rare tumor in the gastrointestinal tract. Imaging studies are essential to determine the relationship with the sphincteric complex and adjacent tissues, and to make a differential diagnosis with other entities such as GISTs, leiomyosarcomas, endometriomas, lipomas, and liposarcomas. In this way, an adequate surgical approach can be planned. To be confirmed as a leiomyoma, it is essential to base the diagnosis on immunohistochemical staining.

\section{CONFLICT OF INTEREST}

No potential conflict of interest relevant to this article was reported.

\section{SUPPLEMENTARY MATERIALS}

Supplementary materials for this study are presented online (available at https://doi.org/10.3393/ac.2020.10.13.1.v001).

\section{REFERENCES}

1. Huilgol RL, Young CJ, Solomon MJ. The gist of it: case reports of a gastrointestinal stromal tumour and a leiomyoma of the anorectum. ANZ J Surg 2003;73:167-9.

2. Dasari BV, Khosraviani K, Irwin TS, Scott M. Perianal leiomyoma involving the anal sphincter. Ulster Med J 2007;76:173-4.

3. Kim HJ, Lee KY, Kim YW. Case report: imaging features of peri- anal leiomyoma. Br J Radiol 2009;82:e168-70.

4. Canda AE, Sarioglu S, Sokmen S. Anal leiomyoma. Surgery 2010; 148:160-1.

5. Alonso Gómez J, Membrives Obrero A, Martínez Cecilia D, Rangel Mendoza Y, Arjona Sánchez A, Roldán de la Rúa J, et al. Real anal leiomyoma: a case report. J Gastrointest Cancer 2011;42:54-6.

6. Sun P, Ou H, Huang S, Wei L, Zhang S, Liu J, et al. Perianal atypical leiomyoma: a case report. Medicine (Baltimore) 2017;96:e8847.

7. Dagmura H, Daldal E, Akbaş A, Daşıran F. A rare anal mass: anal leiomyoma presented as perianal fistula. J Surg Case Rep 2019; 2019:1-3.

8. Campos FG, Leite AF, Araújo SE, Atuí FC, Seid V, Habr-Gama A, et al. Anorectal leiomyomas: report of two cases with different anatomical patterns and literature review. Rev Hosp Clin Fac Med Sao Paulo 2004;59:296-301.

9. Vorobyov GI, Odaryuk TS, Kapuller LL, Shelygin YA, Kornyak BS. Surgical treatment of benign, myomatous rectal tumors. Dis Colon Rectum 1992;35:328-31.

10. Levy AD, Remotti HE, Thompson WM, Sobin LH, Miettinen M. Anorectal gastrointestinal stromal tumors: CT and MR imaging features with clinical and pathologic correlation. AJR Am J Roentgenol 2003;180:1607-12.

11. Hatch KF, Blanchard DK, Hatch GF 3rd, Wertheimer-Hatch L, Davis GB, Foster RS Jr, et al. Tumors of the rectum and anal canal. World J Surg 2000;24:437-43.

12. Park SB, Kim JK, Cho KS. Sonography of endometriosis in infrequent sites. J Clin Ultrasound 2008;36:91-7.

13. Llauger J, Palmer J, Pérez C, Monill J, Ribé J, Moreno A. The normal and pathologic ischiorectal fossa at CT and MR imaging. Radiographics 1998;18:61-82.

14. Espinosa MH, Quan SH. Anal fibrosarcoma: report of a case and review of literature. Dis Colon Rectum 1975;18:522-7.

15. Nappi C, Di Spiezio Sardo A, Mandato VD, Bifulco G, Merello E, Savanelli A, et al. Leiomyomatosis peritonealis disseminata in association with Currarino syndrome? BMC Cancer 2006;6:127.

16. Núñez Martínez O, Salinas Moreno S, Manceñido Marcos N, Pajares Villarroya R, Erdozaín Sosa JC. Rectal leiomyoma: endoscopic resection. Gastroenterol Hepatol 2012;35:373-5. 